\title{
Making Medical Assistance Possible through Smart Watch
}

\author{
Dhruv Bhasin \\ CSE/IT Department \\ ITM University, \\ Sector 23A, Huda, Gurgaon, \\ Haryana 122017, India
}

\author{
Dhruv Sharma \\ CSE/IT Department \\ ITM University, \\ Sector 23A, Huda, Gurgaon, \\ Haryana 122017, India
}

\begin{abstract}
Gone are those days when having a cabled phone was a very big thing, but nowadays, mobile phones have become a basic necessity of life. Technology has grown exponentially in past few decades in every dimension of life. Did anybody ever wonder that one day they would have a small computer on their wrist? A computer that will guide them, assist them in their day to day activities.

It is now possible in the form of a small computerized watch called the Smart Watch, a kind of wearable technology which assists them in day-to-day tasks and also monitors their fitness.

\section{General Terms}

Wearable technology is such which can be worn and performs smart applications like tracking health related information, sync the information with the database etc.

Smart Watch is a mobile device which comes under wearable technology and keeps people updated about their day-to-day task without them checking their Smartphone every time.
\end{abstract}

\section{Keywords}

Smart Watch, wearable technology, medical assistance, future technology, application.

\section{INTRODUCTION}

Smart Watch is a new concept in the gadget industry. Many smart applications using art technologies have been incorporated in it. A detailed time graph has been discussed below that will show people how their lives would be largely affected by Smart Watch in near future. This paper has been organized into various sections. Section 1 focuses on the major components that are involved and the ways they can use the product. Section 2 focuses on the features that are currently available and some of the research has already been done to present the comparison between existing Smart Watches [3, 4, $5,6,7,11]$. And this comparison is presented in table 1 . Section 3 involves future features which could be seen in the near future and are currently worked upon. Also, how our day would look like in near future is depicted in table 2 in section 4. R\&D and Future Work followed by conclusion in Section 5 and 6 respectively. fitness routine or activity $[1,2]$. It will cover all the fitness measures related to walking or jogging like calories burned, distance covered and the speed. Medical Assistance Application will store this data on a database so that at any point of time people can analyze the performance and set goals accordingly. Also, Medical Assistance Application will keep a record of all their prescriptions so that people can take their medicines on time.

\subsection{Process 1: Registration}

Patient and Doctor firstly have to register by filling the detailed form on the website (see figure 1). Both will get their own login credentials i.e. unique id number. Their credentials would be stored on a common database.

\subsection{Process 2: Working Scenario}

Doctors will first login to their system. Patients will then visit to a doctor's clinic (see figure 2). Doctors will then address all their medical problems. Then patients will provide their unique id number to doctors. Doctors will then assign the prescription to patients' account. This prescription would then be synchronized to all the devices containing medical assistance application. This medical assistance application will send notification reminders to all devices regarding the medicine timings and the next due appointment with doctor.

\section{FEATURES}

Once people began looking at the current wearable hardware landscape, they got to know about the many sensors added to give add-on features to the device. Features available in various smart watches in India are depicted in Table 1. The following are the basic features they expect to see in every Smart Watch they buy:-

\subsection{Accelerometer}

Accelerometers are table stakes in the wearable game. They measure body movement to track a person's steps and sleep patterns.

\subsection{Gyroscope}

Gyroscopes measure rotation for a variety of purposes. They feed data into exercise-tracking algorithms, and can sense when people turn their wrists to look at their watch face, thus waking up the display.

\section{COMPONENTS}

Medical Assistance Application is a smart assistance application. This will constantly keep the track of a person's 


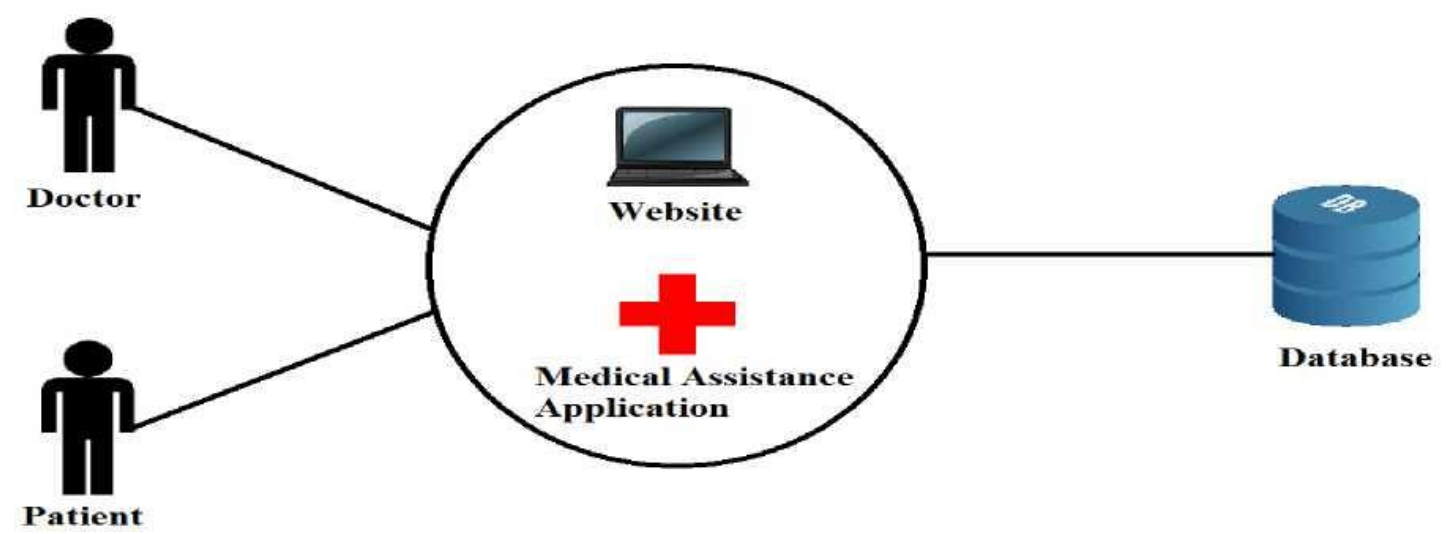

Fig 1: Registration Process

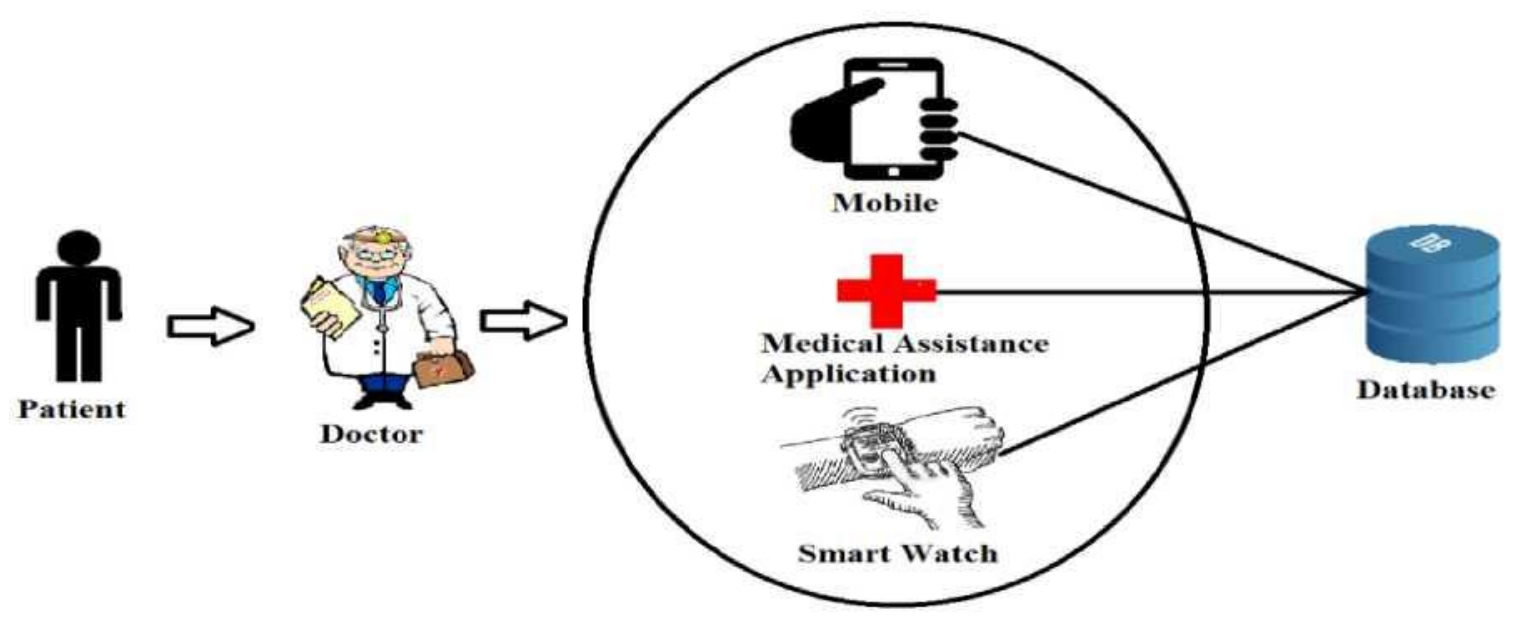

\subsection{Magnetometer}

This is a compass by any other name. It can be used for improved accuracy in motion tracking.

\subsection{Barometric pressure sensor}

This isn't necessarily about supplying the user with weather data. No, the barometer can measure changes in altitude, which is relevant to any runner or cyclist who climbs hills.

\subsection{Ambient temperature sensor}

Another relatively simple sensor that could be used in algorithms that report bio-data. For example, ambient temperature could be compared to skin temperature in the service of determining exertion levels.

\subsection{Heart rate monitor}

It does what it says it does. Basis integrated a heart rate monitor into its B1 Band in late 2012, and Samsung's latest Gear wearable, released this April, also include heart rate monitors. This is basically an optical blood flow sensor, from which heart rate can be divined.

\subsection{GPS}

Doesn't everybody want to know where they're going, and where they've been?

\section{WHAT FEATURES CAN BE ADDED IN FUTURE}

\subsection{Oxymetry sensor}

This one measures blood oxygen, a key data point for reporting accurate pulse rates (and thus heart rates).

\subsection{Skin conductance sensor}

This measures galvanic skin response or, how much a person sweats. The Basis B1 band already has this sensor, which helps calculate exertion levels, and thus calorie-burn numbers.

\subsection{Skin temperature sensor}

Here's another sensor that's already employed in the Basis band. People can get a better idea of how hard they have been exercising if they compare their skin temperature to ambient temperature.

And many more to come, with a glucose level in blood calculator, smart watch will take medical assistance to a whole new level.

\section{HOW SOMEBODY'S DAY WOULD LOOK LIKE IN NEAR FUTURE}


Table 1. A small insight of near future day $[9,10]$

\begin{tabular}{|c|c|c|c|c|l|c|}
\hline & $\begin{array}{c}\text { Apple } \\
\text { iWatch }\end{array}$ & $\begin{array}{c}\text { Samsung } \\
\text { Gear 2 }\end{array}$ & $\begin{array}{c}\text { Moto } \\
\mathbf{3 6 0}\end{array}$ & Pebble Steel & $\begin{array}{l}\text { Adidas } \\
\text { miCoach } \\
\text { Smart run }\end{array}$ & Nike+ \\
\hline $\begin{array}{c}\text { Operating } \\
\text { System }\end{array}$ & Ios & Tizen & $\begin{array}{c}\text { Android } \\
\text { Wear }\end{array}$ & Pebble OS & Android & Nike API \\
\hline $\begin{array}{c}\text { Battery Life } \\
\text { Meart-Rate }\end{array}$ & Unknown & $2-3$ days & a day & $5-7$ days & 8 hours & 1 day \\
\hline Accelerometer & $\mathbf{Y}$ & $\mathbf{Y}$ & $\mathbf{Y}$ & $\mathbf{X}$ & $\mathbf{Y}$ & $\mathbf{Y}$ \\
\hline Gyroscope & $\mathbf{Y}$ & $\mathbf{Y}$ & $\mathbf{Y}$ & $\mathbf{Y}$ & $\mathbf{Y}$ & $\mathbf{Y}$ \\
\hline $\begin{array}{c}\text { Magnetometer } \\
\text { Barometric } \\
\text { pressure sensor }\end{array}$ & N.A. & $\mathbf{Y}$ & $\mathbf{Y}$ & $\mathbf{X}$ & $\mathbf{X}$ & $\mathbf{X}$ \\
$\begin{array}{c}\text { Ambient } \\
\text { temperature } \\
\text { sensor }\end{array}$ & N.A. & $\mathbf{X}$ & $\mathbf{Y}$ & $\mathbf{Y}$ & $\mathbf{X}$ & $\mathbf{X}$ \\
\hline GPS & $\mathbf{Y}$ & $\mathbf{Y}$ & $\mathbf{X}$ & $\mathbf{X}$ & $\mathbf{X}$ & $\mathbf{X}$ \\
\hline $\begin{array}{c}\text { Voice Control } \\
\text { N.A. }\end{array}$ & $\mathbf{Y}$ & $\mathbf{Y}$ & $\mathbf{Y}$ & $\mathbf{X}$ & $\mathbf{X}$ & $\mathbf{X}$ \\
\hline
\end{tabular}

Table 2. A small insight of near future day

\begin{tabular}{|c|c|c|}
\hline Time & Activity & Working \\
\hline $6: 30$ & Wake them up & $\begin{array}{l}\text { Smart watch on their wrist would wake them up without disturbing } \\
\text { others. It will use silent alarm with mild vibration on their arm. It will } \\
\text { also keep track of their sleeping hours and pattern. }\end{array}$ \\
\hline 7:00 & $\begin{array}{l}\text { Morning Exercise } \\
\text { Routine }\end{array}$ & $\begin{array}{l}\text { When they would go out for morning walk or jogging, watch will } \\
\text { provide important data like distance covered, heart-rate, calories } \\
\text { burned. }\end{array}$ \\
\hline 8:00 & $\begin{array}{l}\text { Medical Reminders } \\
\text { Choosing best path }\end{array}$ & $\begin{array}{l}\text { Watch will notify them a about the breakfast timings and if there is } \\
\text { any medicine prescribed to them. } \\
\text { Now when they would leave for office, it will track their movements } \\
\text { and will guide them in selecting the best possible way. }\end{array}$ \\
\hline $14: 00$ & Medical reminder & $\begin{array}{l}\text { It will notify them about the lunch timings. } \\
\text { Again, it will remind them about their medicine, if any. }\end{array}$ \\
\hline $18: 00$ & GPS Tracking & $\begin{array}{l}\text { The GPS in child's watch would track all of the kid's movements. } \\
\text { This can be used as an important security measure to track child's } \\
\text { movements. }\end{array}$ \\
\hline 21:00 & Tasks briefing & $\begin{array}{l}\text { Smart watch will notify them about the dinner and bed time medicine. } \\
\text { And will brief them about whole day's activities. }\end{array}$ \\
\hline 22:00 & $\begin{array}{l}\text { Task scheduler, } \\
\text { Database } \\
\text { synchronization }\end{array}$ & $\begin{array}{l}\text { At bed time, Smart watch will help them in setting up the next day's } \\
\text { schedule and it will start monitoring their sleep. Also, it will sync } \\
\text { whole day's data to database. }\end{array}$ \\
\hline
\end{tabular}




\section{ONGOING R\&D AND FUTURE TECHNOLOGY}

\subsection{Interface}

Graphical user interface [2] between the hardware and user must be user-friendly. It should be such so that any age group would feel comfortable using it.

\subsection{Safety Issues}

Wearable devices should not emit any kind of radiations that have harmful effects on the body [2].

\subsection{Cost and Availability}

These devices must be available at an affordable price. Also, their repair and maintenance cost should be low. Moreover, their availability should not be an issue.

\subsection{Data}

Data [2] collected by these devices should not only be easily transferable but it should remain in an encrypted form. So that, no third party can look into your private data.

\subsection{Weight}

Wearable devices should be light weight.

\subsection{Power Consumption}

These devices should consume low power.

The future looks quite bright, as it was felt when Samsung announced an ARM Cortex-A7 dual-core processor powered mobile medical tech platform called Simband. The watch has a heavy emphasis on health and fitness, full of different sensors, also supports basic functionalities like Bluetooth and Wi-Fi. Simband constantly provides personalized feedback and suggestions to help improve a person's well being, or even schedule an appointment if serious problem is found. The wristband itself is loaded with different kinds of sensors, and since it is modular, people can add new sensors when they become available. The watch shares and collects health data in real time, and work with works with SAMI, Samsung's cloudbased solution [8] for collecting and analyzing sensor-based health data., where healthcare professionals can analyze blood pressure, breathing rate, heart rate and other important health indicators. This can constantly provide personalized feedback and suggestions to help improve their well being, or even schedule an appointment if serious problem is found.

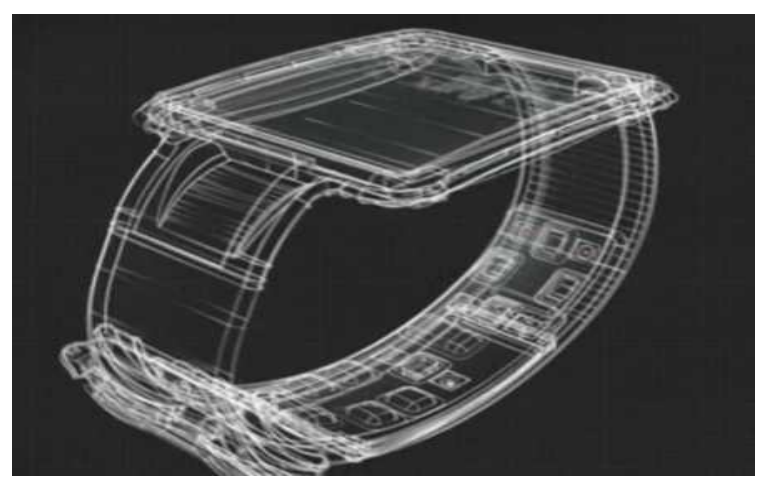

Fig. 3 Samsung's Simband Prototype

It also features a shuttle-style battery that connects to the wristband while people sleep, so they would never have to take it off to charge it up. One major difference between the new Simband and other Smart Watch is that it focuses on individuals who need constant medical attention and not for regular consumers. With Simband, Samsung will be taking the
Medical assistance platform to another level and soon people can expect other competitors to come up with more innovative ideas. Thus, the future looks quite promising.

\section{CONCLUSION}

Wearable technology is a new dimension in science where lot of research and development work is going on. Ranging from fitness, wellness \& healthcare to industrial \& military, Wearable Technology is being used everywhere. It has been considered as a revolution in Science \& Technology. Also, it will ease the way we used to live. Wearable Technology can also be thought as carrying information with yourself and accessing it in the best possible and simplest way. For example while you are driving you need to attend a phone call and your phone is in your pocket, you can use a smart watch to reject and answer that call. Also, while driving you can easily get to know who's calling by simply looking at it. Moreover with this technology interaction and communication between different devices becomes very simple.

In medical field, Wearable Technology has the potential to assist human beings in personalized health care support. This can also be considered as a revolution in the medical science too as it offers cost effective and timely accessible solution. In this field Wearable Technology constantly collects data and stores it in a common place so that it can be easily analyzed and shared. Also, this will give the real time heath status of the wearer.

Thus, it would not be wrong to say that in times yet to come, Wearable Technology could prove for a salient trailblazer ensuring for an esteemed legacy. Also, Wearable Technology can serve in a productive manner when used in the right direction.

\section{ACKNOWLEDGMENT}

We would like to thank Diksha Gaba, of ITM University for her support and guidance.

\section{REFERENCES}

[1] Kyung Chun Lee, Ki Eun Seong, Soon Ju Kang. "SelfOrganizing Watch Platform for Assisting \& Reminding Personal Activity," 2013 IEEE 7th International Conference on Self-Adaptation and Self-Organizing Systems Workshops.

[2] A. Lymberis." Smart Wearable Systems for Personalized Health Management: Current R\&D and Future Challenges," Proceedings of the 25' Annual International Conference of the IEEE EMBS Cancun, Mexico * September 17-21,2003.

[3] http://moto360.motorola.com/

[4] http://www.apple.com/watch/health-and-fitness/

[5] http://androidcentral.com/samsung-gear-2-specs/

[6] www.micoach.addias.com/in/smartrun

[7] www.securenikeplus.nike.com/plus/products/sport_watch/

[8] www.cnet.com/products/samsung-simband/

[9] http://www. gauravgarg216. com/apps/blog/

[10] http://edition.cnn.com/2013/07/25/tech/innovation/bionic -fashion-wearable-tech-2015/

[11] https://getpebble.com/pebble/ 